\title{
A REVIEW ON LEGAL TRACEABILITY OF GNSS MEASUREMENTS IN THE MALAYSIAN CADASTRAL PRACTICE
}

\author{
J. Gill, N. S. Shariff, K. M. Omar, A. H. M. Din, Z. M. Amin
}

Faculty of Geoinformation and Real Estate, Universiti Teknologi Malaysia, 81310 Skudai, Johor - jespal.g@gmail.com

KEY WORDS: Legal Traceability, Cadastre, Network RTK, MyRTKnet

\begin{abstract}
:
As the dependency on Global Navigation Satellite System (GNSS) in surveying has been growing over the years, the need for legal traceability of GNSS measurements has become a significant matter. In Malaysia, with the advent of the Malaysia Real-time Kinematic Network (MyRTKnet), GNSS surveying has revolutionised land survey and mapping. Correspondingly, the Department of Survey and Mapping Malaysia (DSMM) amended and published standard regulations and guidelines concerning cadastral survey, i.e., Cadastral Survey Regulations 2009, to include GNSS measurements. However, these regulations and guidelines has not comprehensively incorporated legal traceability of GNSS measurements; which is a prerequisite for cadastral surveys as it requires reliable and conclusive evidence for issues such as boundary disputes. The first objective of this paper is to review and discuss the legal traceability of GNSS measurements. Secondly, it will highlight the current practice and issues, i.e., with regard to legal traceability, within the present Malaysian cadastral regulation and guidelines, in relation to the prevalently adopted Network RTK (N-RTK) technique, GNSS instrument calibrations, and reference stations' accuracy. Lastly, a rudimentary best practice guideline for GNSS surveying in cadastral survey for Malaysia is proposed. It is expected that this paper will contribute to the implementation of a best practice guideline, which is inclusive of legal traceability of GNSS measurements, for the Malaysian cadastral practice.
\end{abstract}

\section{INTRODUCTION}

The reliability and constant advancements in GNSS have led it to be one of the most commonly used technologies; from navigation to surveying and mapping, and even wide-scale studies such as geodynamics and geophysics. This technology has not only been applied in engineering surveys, like mapping and topographical survey, but as well in cadastral surveys to determine land boundaries. However, unlike traditional instruments, the measurements determined via GNSS surveying, specifically in Malaysia, are currently not subject to any sort of validation, primarily involving the Network Real-Time Kinematic (N-RTK) technique.

Validation, here, connotes the compliance of surveying measurements to the international or national measurement standard, or, in specie, its 'traceability' to the SI standard (Martin, 2012). This validation is termed 'legal traceability' as only by employing the concept of traceability, measurements then become 'legal' (Ses et al., 2000). Legal traceability, thence, provides users and authorities a sense of certainty on the GNSS survey carried out as it ensures that a measurement is an accurate representation of what is measured. Bissett (2008) stated that legal traceability is "the ability for surveyors to remeasure land parcels based on the documented measurements of another surveyor with a common uniformity of measurement.”

Traceability is defined in VIM (2012) as "property of a measurement result whereby the result can be related to a reference through a documented unbroken chain of calibrations, each contributing to the measurement uncertainty.” Therefore, by employing traceability for GNSS measurements, GNSS equipment has to include a set of calibrations to be certified for use, much like the electronic distance measurement (EDM) equipment. The certified EDM baselines will enable the length measured, i.e., in metres, to be directly traceable to the International Standard (SI); hence, contributing to the measurement uncertainty. Generally, with reference to the legal traceability of EDM measurements, it is apparent that if measurements are deemed legally traceable, it has to consider all instrument errors to provide the best possible measurement results with respect to the SI standard. Therefore, abiding by the previous statement, GNSS measurements are required to provide results that are repeatable, i.e., minimum uncertainty, over a certain period and must provide documentation of its traceability back to the SI standard via calibrations. The question then is whether the concept of legal traceability should be implemented in GNSS measurement results or would adopting a best practice for GNSS measurements suffice to obtain repeatable results?

In Malaysia, the concept of legal traceability has been generally discussed in the paper by Ses et al. (2000). The paper studies the applicability of the 1999 GNSS Cadastral Survey Guideline for surveyors to carry out cadastral surveying using GNSS techniques. According to the authors, measurements are only considered legally traceable if it has carried out various test/calibration procedures and the survey has followed the "recommended practices for field and office procedures", of which both are described in the guideline. However, during the year 2000, RTK techniques were not available in Malaysia; hence, the previous GNSS Cadastral Survey Guideline was revised to include RTK techniques, i.e., Cadastral Survey Regulations 2009.

Therefore, the first objective of this paper is to review and discuss the legal traceability of GNSS measurements. Secondly, it will highlight the current practice and issues, i.e., with regard to legal traceability, within the present Malaysian cadastral regulation and guidelines, in relation to the prevalently adopted 
N-RTK technique, GNSS instrument calibrations, and reference stations' accuracy. Lastly, a rudimentary best practice guideline for GNSS surveying in cadastre for Malaysia is proposed.

\section{LEGAL TRACEABILITY OF GNSS MEASUREMENT IN MALAYSIA}

According to Higgins (2001), GNSS surveying is much about best practice rather than traceability. The justification behind this statement is on the method of which GNSS surveying achieves its measurement results. The major issues of EDM length measurements concerned with legal traceability are its instrument errors; however, with GNSS, it is not a simple matter for its measurement results to be legally traceable. Firstly, the relevant result or derivative of GNSS measurement for legal traceability needs to be determined and, secondly, the errors associated with the impediment of legal traceability have to be identified.

The selection of position, instead of baselines, as the derivative of GNSS measurements is evident with the advent of RTK. RTK techniques has revolutionised GNSS surveying, causing it to be the most accepted technique in surveying as it provides real-time results at centimetre-level accuracy (Aponte et al., 2009). Therefore, a method to implement legal traceability of positions for GNSS surveying should be developed.

In order for positions to be legally traceable, its measurement errors must be minimised to achieve repeatable and accurate results. However, errors associated with GNSS measurement are not completely isolated within instrument errors. Principally, there are two types of errors that perturb GNSS measurements, which consequently cause GNSS measurement results to be inaccurate and unrepeatable: systematic and gross errors. With an appropriate observation model, e.g., double difference carrier phase observable and processing algorithms, e.g., ambiguity resolution, atmospheric modelling, precise orbits, clock corrections, etc., systematic errors are considerably reduced. Hence, the remaining errors are most probably due to sitedependent errors such as multipath and local atmospheric effects, and gross errors such as incorrect phase ambiguity resolution (Higgins, 2001). As these remaining errors are not due to instrumental issues, calibration alone is unsuitable for traceability. Under these circumstances, GNSS surveying is more about best practice compared to legal traceability.

As a result, GNSS survey requires a set of procedural guidelines which will ensure that the required survey accuracy is achieved in all conditions (NLWRA, 2008). A best practice guideline should be developed to provide instructions to surveyors to achieve acceptable results. Thus, best practice guidelines will provide repeatable and accurate results in-line with the purpose of legal traceability, rather than a 'chain of calibrations'. Furthermore, the Department of Standard Malaysia (2008) stated "where such traceability is not technically possible or reasonable, the laboratory and the customer and other interested parties may agree to using certified reference materials provided by a competent supplier or using specified methods and/or consensus standards that are clearly described and agreed by all parties concerned". This means that it is not obligatory to demonstrate traceability of measurement results that are considered unrealistic. Hence, this statement can be applied in the context of GNSS measurement results as well. All in all, it is conclusive that GNSS measurements can principally be traceable with the employment of a standard best practice.

The Malaysian Cadastral Survey Regulations 2009 provides a best practice guideline for surveyors to conduct cadastral survey using GNSS. However, a few issues have arisen recently, primarily concerning the best practice adopted for the N-RTK technique and instrument calibration. Thus, these issues are assessed in terms of: (1) the reliability of N-RTK for cadastral survey, i.e., consistency of observed results with respect to spatial and temporal effects, and (2) GNSS instrument calibration.

\section{CURRENT PRACTICE AND ISSUES WITHIN THE PRESENT MALAYSIAN CADASTRAL REGULATIONS AND GUIDELINES}

This section discusses on the current practice and its issues with regard to the Malaysian cadastral regulations and guidelines, i.e., The Malaysian Cadastral Survey Regulations 2009 and the GNSS Instrument Calibration Guidelines 2008. The practice and issues are focused on two aspects that do not conform well with legal traceability: the N-RTK technique, GNSS instrument calibration method, and the MyRTKnet reference stations accuracy.

\subsection{The Practice and Issues Regarding Network-Based Real Time Kinematic Technique in Malaysia}

With reference to the Malaysian Cadastral Survey Regulations 2009, N-RTK can be used to establish the datum for initiation of the cadastral survey via Cadastral Reference Marks (CRM) known points surveyed using GNSS techniques. The reader is directed to the Cadastral Survey Regulation 2009 for further information.

Studies by Hakli (2007), Gordini et al. (2006), Dao et al. (2004) and Aponte et al. (2009) show that by utilising N-RTK, positional accuracy at centimetre-level can be achieved. Basically, the concept of N-RTK is to model distancedependent errors that consist of ionospheric, tropospheric and orbital errors within a Continuously Operating Reference Station (CORS) network, which are then transmitted as network corrections to users, epoch by epoch. In Malaysia, a commercial N-RTK service is provided by DSMM via its CORS network, i.e., MyRTKnet. The MyRTKnet N-RTK utilises the Virtual Reference Station (VRS) method to provide N-RTK corrections for users.

There are two primary factors that affect the quality of network corrections in N-RTK for cadastral survey: the spatial (network geometry) and temporal (time of day) factors, which are discussed extensively as they are the major determinant of positional accuracy in N-RTK.

\subsubsection{Network Geometry}

In the equatorial region, there are severe ionospheric activities that result in difficulty for the network ambiguity resolution process (Hu et al., 2003), especially if inter-station distances are over 40 - $50 \mathrm{~km}$ (Cannon et al., 2001; Willgalis et al., 2001). It is because ionospheric errors are less spatially correlated over long baselines. 


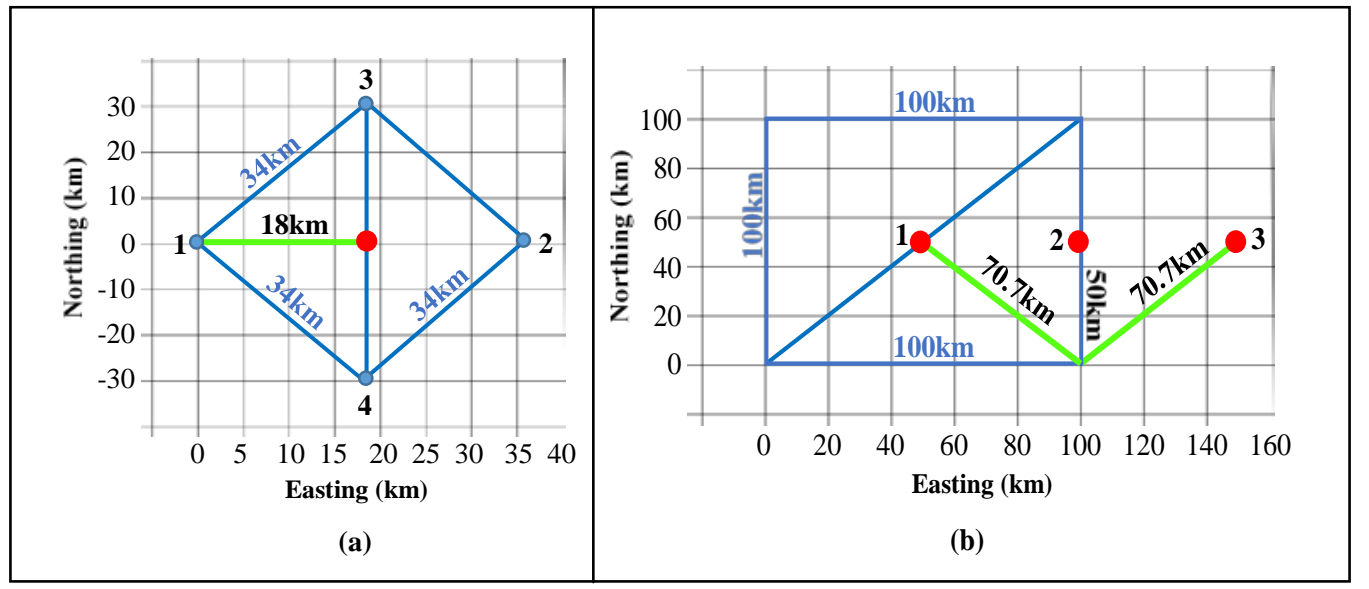

Figure 1. Two network geometries: (a) 4 reference stations with inter-station distances up to $34 \mathrm{~km}$, (b) 4 reference stations with inter-station distances up to $100 \mathrm{~km}$. Blue and red dots represent reference and user stations, respectively (Alves et al, 2003)

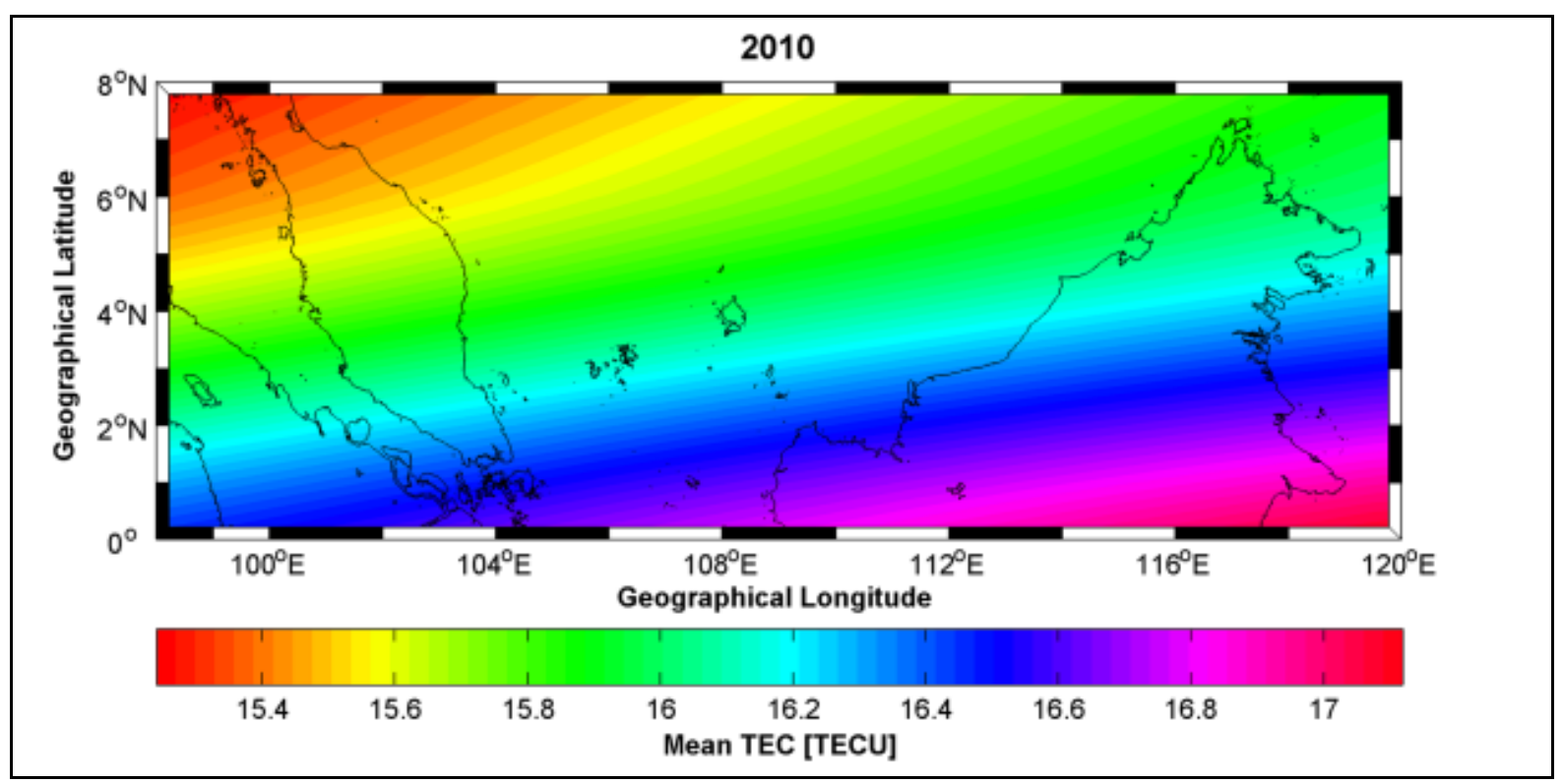

Figure 2. Spatial variation of an average TEC during year 2010 over Malaysia (Musa et al., 2012)

Alves et al. (2003) and Geisler (2006) evaluated the impact of network design and inter-station distances which had shown high variation in the percentage of ambiguity resolution and improvements in positioning accuracy. Figure 1 shows two network geometries: (a) 4 reference stations with inter-station distances up to $34 \mathrm{~km}$, (b) 4 reference stations with inter-station distances up to $100 \mathrm{~km}$. The results indicated that network (a) is more preferable than network (b) due to the inter-station distances are short, thus efficiently reducing distance-dependent errors. Incidentally, network (b) demonstrates that different user location has different positioning results, whereby the user at the centre of network has a higher positioning accuracy than the user on the edge or outside of the network. This is because the centre position has better distance-dependent errors modelling compared to the edge and outside of the network.
As Malaysia is situated within the equatorial region, the ionospheric conditions are severe as well. The study by Musa et al. (2012) verifies that spatial variation of Total Electron Content (TEC) over Malaysia has an inhomogeneous gradient in both North-South and East-West directions (see figure 2). The TEC values are typically used to illustrate the ionospheric conditions; as higher the TEC value, the larger the ionospheric error (Hoffman-Wellenhof et al., 2008). Hence, due to inhomogeneous gradient and high TEC values over Malaysia, the ionospheric errors would have consequential correlation issues over long baselines. Particularly, with spacing between 30 and $120 \mathrm{~km}$ between the 78 MyRTKnet station throughout the country (Jamil et al., 2010), this will lead to difficulty of network ambiguity resolution and uncertainty on the quality of network corrections which restricts achieving high accuracy in positioning. 
The International Archives of the Photogrammetry, Remote Sensing and Spatial Information Sciences, Volume XLII-4/W1, 2016 International Conference on Geomatic and Geospatial Technology (GGT) 2016, 3-5 October 2016, Kuala Lumpur, Malaysia

\subsubsection{Time of Day}

The N-RTK performance also depends on time of day. Tests on N-RTK has been conducted for two days at different times of day, i.e., morning, afternoon and night in 2010, by using ISKANDARnet N-RTK - a research-based N-RTK system developed by Universiti Teknologi Malaysia (Shariff et al., 2015). The results in figure 3 illustrate pie charts for fixed, float and unresolved ambiguities in percentage, denoted by blue, green and red colours, respectively. The result indicate that morning sessions had the highest number of ambiguity fixed solutions (82.7\% and $71.4 \%$ ), followed by the night sessions (61.2\% and 59.6\%) and, lastly, the noon sessions (5.3\% and $24.8 \%$ ); whereby the values in the brackets represent Day of Year (DoY) 182 and 183, respectively.
It is signified that the N-RTK results are inconsistent due to variability of ionospheric activities, which are especially high during the noon sessions. As the ionospheric errors typically depend on TEC value, figure 4 shows that the TEC value during noon on DoY 182 (blue line) and 183 (red line) are significantly higher compared to the morning and at night sessions.

Therefore, the present state of N-RTK in Malaysia is susceptible to spatial and temporal errors which in turn provides nonrepeatable results. This then opposes the requirement for traceability, causing it to be unsuitable for cadastral surveys. Nevertheless, it does not mean that N-RTK should be not be used at all, but provides prospects for improvement in order for N-RTK to be legally traceable. These improvements are suggested in table 1 in the conclusion section.

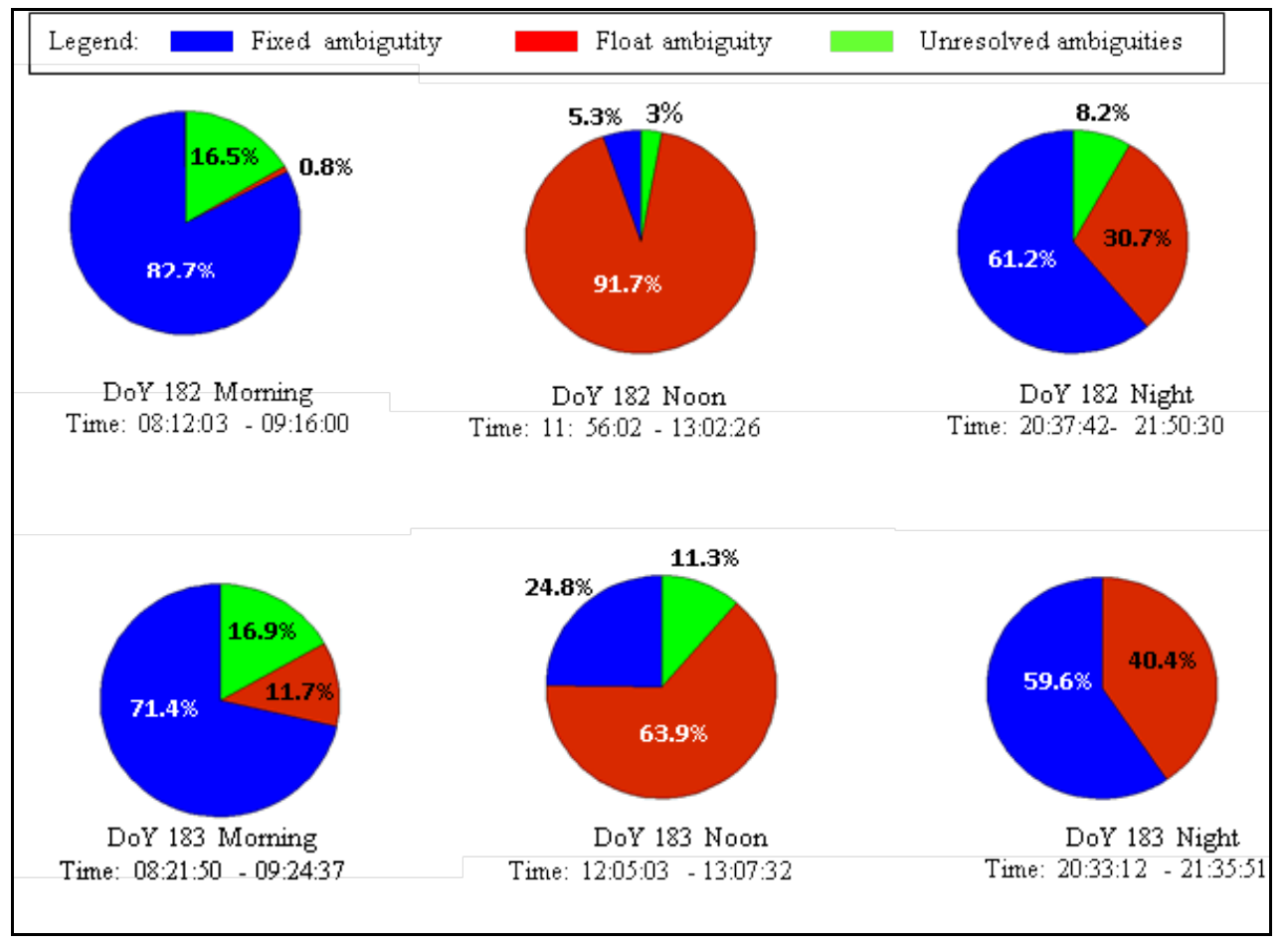

Figure 3. Percentage of ambiguity resolution for DoY 182 and 183

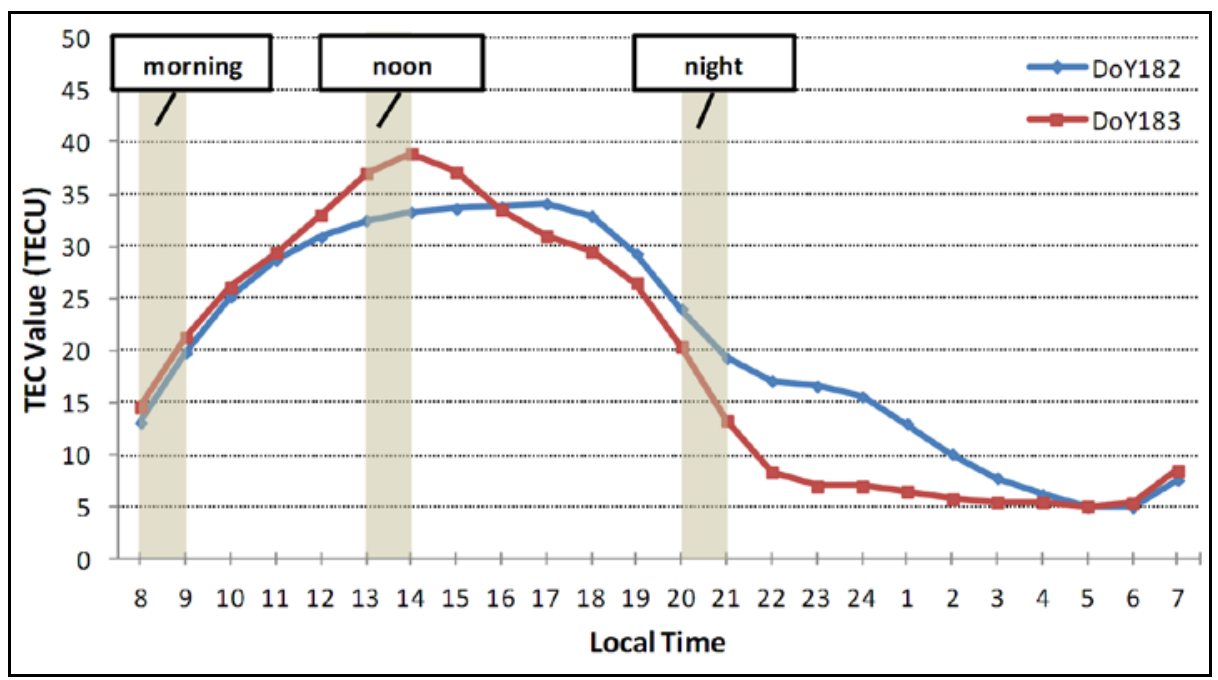

Figure 4. TEC values during GNSS observations on DoY 182 (blue line) and 183 (red line) 


\subsection{GNSS Instrument Calibration}

Calibrations are carried out to ensure accurate and repeatable results by GNSS instruments; thus, conforming to the purpose of traceability. Calibration establishes a relation between the quantity values with measurement uncertainties, provided by measurement standards (Bissett, 2008). However, as there is no agreed upon measurement standard for GNSS as yet, most GNSS instrument manufacturers provide the measurement uncertainties based on a 'value standard', i.e., a monument with 'known' coordinates. Therefore, the term 'chain of calibrations' is not necessarily applied for GNSS instruments. Nevertheless, calibration should not be confused with verification, nor validation, as verification mainly serves as an indicator to qualify the instrument's performance (Martin, 2012).

Although it has been concurred here that the legal traceability of GNSS measurements results is mainly based on best practice, verifications and calibrations are still needed in achieving traceable results as it is the first step in reducing systematic errors. Hence, it is an integral part of the best practice guideline.

With reference to the Malaysian regulations and guidelines on Malaysian Regulations and Guidelines on GNSS Instrument Calibration Guidelines 2008 and Cadastral Survey Best Practice Guidelines 2009, there are two available verification methods: (1) real-time data via N-RTK technique, and (2) post-processed with VRS data. A few calibration EDM/GNSS sites have been established around Malaysia by DSMM, e.g., Alor Setar (Kedah), Dungun (Terengganu), Wilayah Persekutuan Labuan, etc. By adopting the coordinates from the pillars of these calibration sites, verification is carried out via comparing the measured coordinates with the 'known' coordinates of the pillar. These comparisons then verify the instrument capability to perform GNSS surveying. According the regulations and guidelines, GNSS instrument verification must be carried out annually.

The verification using real-time data requires 3 datasets; of which, for each dataset, 3 epochs with 10 seconds of $1 \mathrm{~Hz}$ data are observed, where each epoch has different initialisations. The instrument must be mounted on a separate calibration pillar for each dataset. The data for each epoch will then be averaged. For each dataset, the difference between the observed coordinates of each epoch and the 'known' coordinates must be below $0.030 \mathrm{~m}$ for the north and east component and $0.060 \mathrm{~m}$ for the height component. Furthermore, the observation residuals for each observation within an epoch which are 3 times larger than the RMS must be removed from the epoch; a maximum of 3 observations can be removed.

As for the post-processed method, it uses 2 types of data depending on the capability of the instrument, where the procedure is almost similar with real-time method. For GNSS instruments with RTK capabilities, static/kinematic data with at least 50 seconds of $1 \mathrm{~Hz}$ data for each epoch is required, where both static and RTK data are observed. As for conventional GNSS instruments, i.e., no RTK capabilities, static data with at least 5 minutes of $1 \mathrm{~Hz}$ data for each epoch is required. 3 datasets are needed for both types of instruments; where for each dataset, 2 epochs are observed. The instrument must be mounted on a separate calibration pillar for each dataset as well. Next is the post-processing phase where baseline processing between the VRS and instrument is carried out. There are two criteria that need to be fulfilled. First, the RMS of baseline between the VRS and instrument has to be below $0.02 \mathrm{~m}$. Second, the coordinate differences between the observed coordinates and the 'known' coordinates of the pillar have to be within the same values stated in the real-time data method.

Once either verification methods are within the criteria, the instrument then qualifies for use in the field. These verification procedures provide adequate instrument verification as it evaluates the instrument's performance in terms of accuracy and repeatability. Therefore, to emphasize, the only issue is that the time interval between each dataset should be stated, whereby it takes into account the temporal effects as well, especially with regard to the employment of RTK techniques.

Presently, there are no internationally agreed upon standard for GNSS instrument verification. Despite that, in 2015, the ISO 17123-8:2015 "GNSS field measurement systems in real time kinematic (RTK)" is available, which enables determining and evaluating the repeatability of GNSS field measurement systems in RTK. The standard has 2 types of tests: (1) simplified test procedure, and (2) full test procedure. The full test procedure seems to be an ideal method for verification of instrument's performance as it includes statistical tests, e.g., Fischer test, to investigate whether the calculated standard deviation is within the standard deviation given by the manufacturer. As the Malaysian verification method is sufficient presently, details on the standard's verification procedure are not discussed here. For the standard's verification procedure, refer to ISO 171238:2015.

At present, the Malaysian verification method is satisfactory as it effectively evaluates the GNSS instrument's accuracy and repeatability; hence, providing, to an extent, 'traceable' measurement results. The only issues regarding this verification method are: (1) its absence of stating the time interval between datasets, whereby datasets could be observed at different times of day, i.e., morning, noon, and evening, (2) statistical tests involving standard deviation which is the best representative of measurement uncertainties, i.e., the main requirement for traceability, and (3) uncertain distances between the MyRTKnet reference stations which may result in low ionospheric error correlations.

\subsection{MyRTKnet reference stations accuracy}

The GNSS reference CORS network of a country is suitable to be the benchmark of what coordinates are to be deemed legally traceable, or, in other words, it becomes the 'value standard' for position. On the other hand, crustal deformation due to tectonic motion and local effects, such as land subsidence, will shift the reference station coordinates over time; displacing them further from the specified reference epoch. Hence, the 'value standard' for position has to be kept up-to-date.

With GDM2000 aligned to International Terrestrial Reference Frame 2000 (ITRF2000) at epoch 2006, and presence of earthquakes and seismic motions, it is evident that the MyRTKnet coordinates has been shifted (see Shariff et al., 2014; Gill et al., 2015). Though these reference coordinates can, without a doubt, be used for local surveys, it is not appropriately valid for legal traceability as the coordinates can only be traced to MyRTKnet.

For a proper traceability, the coordinates should be traceable to the ITRF, of which, presently, all national datums and satellite 
systems, i.e., GNSS, GLONASS, are aligned to. Incidentally, the current version is ITRF2014. However, this issue is highly debatable as the main question that arises is, "what reference network should be the coordinates be traceable to?" As aforementioned, for local surveys, e.g., cadastral surveys, traceability to the MyRTKnet stations would be sufficient; however, it would then be impossible to coordinate Malaysia's measurements with the measurements of other countries.

\section{CONCLUSION}

Overall, the cadastral survey regulations and guidelines for Malaysia are sufficient as a best practice guideline for the use of GNSS. Nonetheless, certain improvements could be carried out in order to achieve repeatable results; subsequently, legal traceability. Table 1 describes the proposed further improvements to the best practice guideline with respect to the issues outlined in the previous sections of the paper.

In summation, legal traceability of GNSS measurements is vital in order to provide results that are accurate and repeatable, especially in a legal perspective, as GNSS techniques, e.g., NRTK, are presently primarily utilised for surveying and mapping. Without legal traceability, cadastral surveying, for instance, will be subjected to debate as there is an absence of definite evidence that measurements made from GNSS techniques are reliable and legitimate. Therefore, legal traceability should be employed in the surveying field, particularly for GNSS surveying, as part of an effort to warrant the use of GNSS for legal purposes, e.g., cadastre.

\begin{tabular}{lll}
\hline \multicolumn{1}{c}{ Issue } & & \multicolumn{1}{c}{ Suggestions } \\
\hline & i) & $\begin{array}{l}\text { Establishment of more stations: to reduce Inter-CORS distances to accommodate better accuracy of } \\
\text { network corrections wherever within the network. }\end{array}$ \\
$\begin{array}{l}\text { The reliability } \\
\text { of } \boldsymbol{N} \text {-RTK }\end{array}$ & ii) & $\begin{array}{l}\text { Improve network corrections by introducing regional atmospheric models. } \\
\text { N-RTK techniques are unable to provide proper quality control, as N-RTK may provide incorrect } \\
\text { ambiguity fix and dependent on time of day and network geometry. Hence, rapid static techniques } \\
\text { should still be preferred over N-RTK, unless suggestion (i) is made possible. } \\
\text { In future, Precise Point Positioning (PPP) technique could be employed for CRM establishment, as } \\
\text { PPP is able to provide centimetre-level accuracy and precise results. }\end{array}$ \\
$\begin{array}{l}\text { GNSS } \\
\begin{array}{l}\text { instrument } \\
\text { calibration }\end{array}\end{array}$ & i) & $\begin{array}{l}\text { The best verification method is still static observations connected to CORS with post-processed } \\
\text { double differenced observables. } \\
\text { Implement ISO 17123-8:2015 procedures for verification. }\end{array}$ \\
\hline $\begin{array}{l}\text { GNSS } \\
\text { reference } \\
\text { station } \\
\text { accuracy }\end{array}$ & i) & $\begin{array}{l}\text { Update GDM2000 regularly in order to maintain the alignment of the national geocentric datum to } \\
\text { the international standard, i.e., ITRF. }\end{array}$ \\
\hline
\end{tabular}

Table 1. Suggestions to improve the best practice guideline

\section{ACKNOWLEDGEMENTS}

The authors would like to express our gratitude to MOHE, UTM Research University Grant (RUG), Vote No. 12H99 and $11 \mathrm{~J} 21$ for funding this study.

\section{REFERENCES}

Alves, P., Ahn, Y. W. and Lachapelle, G., 2003. The Effects of Network Geometry on Network RTK using Simulated GPS data. Proc. 16th International Technical Meeting of the Satellite Division of the Institute of Navigation (ION GNSS/GNSS 2003). 9-12 September, Poland.

Aponte, J., Meng, X., Hill, C., Moore, T., Burbidge, M. and Dodson, A., 2009. Quality Assessment of a Network-based RTK GPS Service in UK. Journal of Applied Geodesy, 3(1), pp. 25-34.

Bissett, M. J., 2008. Investigation on utilising Real Time Kinematic (RTK) Global Navigation Satellite Systems (GNSS) for Electronic Distance Measurement (EDM) Baseline Calibration and Traceability of Measurement. Dissertation Bachelor of Spatial Science (Surveying). Faculty of
Engineering and Surveying, University of Southern Queensland.

Cadastral Survey Best Practice Guidelines, 2009. Garis Panduan Amalan Kerja Ukur Kadaster dalam Persekitaran eKadaster. Pekeliling Ketua Pengarah Ukur dan Pemetaan Bilangan 6 Tahun 2009.

Cadastral Survey Regulation, 2009. Peraturan Ukur Kadaster 2009. Pekeliling Ketua Pengarah Ukur Dan Pemetaan Bilangan 5 Tahun 2009.

Cannon, M. E., Lachapelle, G., Alves, P. and Fortes, L. P., 2001. GPS RTK Positioning Using a Regional Reference Netwaork: Theory and Results. Proc. GNSS International Symposium. 8-11 May, Seville.

Dao, T. H. D., Alves, P. and Lachapelle, G., 2004. Performance Evaluation of Multiple Reference Station GPS RTK for a Medium Scale Network. Journal of Global Positioning Systems, 3(1-2), pp. 173-182.

Department of Standards Malaysia, 2008. Samm Policy 2 (SP2) - Policy on Traceability of Measurement Results (Laboratory Accreditation Scheme of Malaysia: MS ISO/IEC 17025). 
Geisler, I., 2006. Performance Improvement of Network RTK Positioning. Proc. 2006 National Technical Meeting of the Institute of Navigation. 18 - 20 January, Monterey, CA.

Gill, J., Shariff, N. S., Omar, K., and Amin, Z. M., 2015. Tectonic motion of Malaysia: Analysis from years 2001 to 2013, ISPRS Annals of the Photogrammetry, Remote Sensing and Spatial Information Sciences, Vol. II-2/W2, pp. 199-206. Copernicus Publications.

Gordini, C., Kealy, A. N., Grgich, P. M. and Hale, M. J., 2006. Testing and Evaluation of a GPS CORS Network for Real Time Centimetric Positioning - The Victoria GPSnetTM. Proc. International Global Navigation Satellite Systems Society. 17 21 July, Holiday Inn Surfers Paradise, Australia.

Higgins, M., 2001. Guidelines for GPS Surveying In Australia. Proc. FIG Working Week 2001: New Technology for a New Century. 6-11 May, Seoul, Republic of Korea.

Hofmann-Wellenhof, B., Lichtenegger, H. and Wasle, E., 2008. GNSS Global Navigation Satellite Systems GPS, GLONASS, Galileo and more. New York: Springer-Verlag Wien.

Hu, G., Khoo, V. H. S., Goh, P. C. and Law, C. L., 2003. Development and Assessment of GPS Virtual Reference Station for RTK Positioning. Journal of Geodesy, 77 (5-6), pp. 292302.

Häkli, P., 2007. The Virtual Reference Station Concept in Finland - A Case Study. Survey Review, 39 (304), pp. 145-155.

International Vocabulary of Basic and General Terms in Metrology (VIM), 2012. JCGM Guidance Document. JCGM 200:2012(E/F).

ISO/CD 17123-8:2015, 2015. Optics and Optical Instruments Field Procedures for Testing Geodetic and Surveying Instruments. Part 8: GNSS Field Measurements in Real Time Kinematic (RTK).

Jamil, H., Mohamed, A. and Chang, D., 2010. The Malaysia Real-Time Kinematic GNSS Network (MyRTKnet) in 2010 and Beyond. Proc. FIG Congress 2010, 11-16 April, Sydney, Australia.

Musa, T. A., Leong, S. K., Abdullah, K. A. and Othman, R., 2012. ISKANDARnet IOMOS: Near real-time equatorial space weather monitoring and alert system in Peninsular Malaysia. Space Weather, 10 (11).

Malaysian Regulations and Guidelines on GNSS Instrument Calibration Guidelines, 2008. Garis Panduan Mengenai Ujian Alat Sistem Penentududukan Sejagat (GNSS) yang Menggunakan Perkhidmatan Malaysian RTK GNSS Network (MyRTKnet). Pekeliling Ketua Pengarah Ukur dan Pemetaan Bilangan 1 Tahun 2008.

Martin, D., 2012. Standards and Traceability of a Terrestrial Reference Frames/GNSS Proc. IAG/FIG Commision 5/ICG Technical. Seminar on Reference Frame in Practice, 4-5 May, Rome, Italy.

NLWRA, 2008. Module 10: Introduction to GPS and Best Practice Guidelines. Australia: Land and Water Australia.
Ses, S., Kadir, M., Tong, C. W., Boo, T. C. and Rizos, C., 2000. Potential Use of GPS for Cadastral Surveys in Malaysia. Proc. 40th Aust. \& 6th S.E.Asian Surveyors Congress, 30 October - 5 November, Fremantle, Australia.

Shariff, N. S., Musa, T. A., Ses, S., Musliman, I. A. and Lee, H. -K., 2015. Performance analysis of ISKANDARnet: a researchbased network RTK positioning system. Journal of Spatial Science, 60(2), pp. 365-386.

Shariff, N. S., Musa, T. A., Omar, K., \& Othman, R., 2014. The Geocentric Datum of Malaysia: Preliminary Assessment and Implications. In Geoinformation for Informed Decisions, pp. 71-83. Springer International Publishing.

Willgalis, S., Seeber, G. and Menge, F., 2001. Implementation of a GPS Reference Network for Real-Time Positioning in Recife, Brazil. Proc. 14th International Technical Meeting of the Satellite Division of the Institute of Navigation, 11-14 September, Salt Lake City, UT. 